\title{
Comparative Study of the Vertebral Heart Scale (VHS) and the Cardiothoracic Ratio (CTR) in Healthy Poodle Breed dogs
}

\author{
Gisllyana Medeiros Azevedo', Gerson Tavares Pessoa', Laecio da Silva Moura', \\ Francisco das Chagas Araújo Sousa ${ }^{2}$, Renan Paraguassu de Sá Rodrigues ${ }^{3}$, Marina Pinto Sanches ${ }^{3}$, \\ Rayssa Dourado Fontenele ${ }^{3}$, Maria Angélica Parentes da Silva Barbosa ${ }^{3}$, Willams Costa Neves ${ }^{4}$, \\ João Macedo de Sousa ${ }^{5}$ \& Flávio Ribeiro Alves ${ }^{4}$
}

\begin{abstract}
Background: Veterinary cardiology has been widely divulged, especially because of the search for diagnostic methods that allow early identification of heart disease in companion animals. Several techniques are available, such as digital radiography (DR), computerized tomography (CT) and magnetic resonance (MR) that are being applied to patients with various diseases. VHS has been widely used in clinical practice in veterinary medicine as a way to diagnose heart size increases in lateral thoracic radiography in small animals. Cardiothoracic ratio (CTR) is a predictive factor for cardiac insufficiency in humans. In veterinary medicine, this index is still little used. The objective of the present study was to compare the vertebral heart scale (VHS) and cardiothoracic ratio (CTR) to assess changes in the size of the cardiac silhouette dogs in thoracic radiographs.

Materials, Methods \& Results: The VHS and CTR of forty healthy poodle breed dogs (20 males and 20 females) from University Veterinary Hospital at the Federal University of Piauí were assessed. The animals were placed in supine and lateral decubitus, to obtain radiographic images in dorsoventral (DV) and right and left laterolateral projections of the thoracic region. The images acquired on the photosensitive radiographic chassis were analyzed by digital radiographic image system installed in the Image Diagnosis Service of the University Veterinary Hospital -HVU/UFPI. VHS (Vertebral Heart Scale) measurements were taken using the sum of the heart length and heart width at its greatest diameter, comparing with the vertebral bodies from the fourth thoracic vertebra (T4). The CTR was assessed by comparing the greatest width of the heart silhouette and the distance between the thoracic walls at height T8. The heart width was measured from the two greatest distances (ML and MR), from the vertical line that divides the limit between the right and left sides of the heart, at the point of its greatest diameter. Similarly, the thoracic width was measured at the point of greatest thoracic diameter (MTD). The mean of the VHS and CTR in the males was $9.83 \pm 0.85 \mathrm{v}$ and $0.48 \pm 0.05$, respectively. The females showed values of $9.65 \pm 0.65 \mathrm{v}$ and $0.50 \pm 0.03$, respectively $(P>0.05)$. The mean of the VHS and CTR, considering males and females, was $9.72 \pm 0.73 \mathrm{v}$ and $0.48 \pm 0.04$, respectively. VHS and weight correlated positively $(\mathrm{r}=0.96)$, as the CTR and weight $(r=0.94)$. VHS and age showed high correlation $(r=0.96)$ as CTR and age $(r=0.93)$. VHS and CTR showed high correlation $(\mathrm{r}=0.96)$.

Discussion: Although congenital malformations and genetic diseases can occur, the acquired heart diseases correspond to most of the complications found in dogs. VHS increases considerably 6 to 12 months before the development of congestive heart failure (CHF). The poodles studied, considering the universe of males and females $(P<0.05)$, presented mean VHS values of $9.72 \pm 0.73 \mathrm{v}$. Similarly, there was no significant difference between genders for VHS measured in right and left decubitus in normal dogs. The cardiothoracic ratio measured for the poodles studied showed mean values of $0.48 \pm 0.05$. In humans, values below 0.5 are considered normal, while values above this may indicate the presence of cardiomegaly. The CTR is intimately related to the volume of the left ventricle and CTR values above 0.5 in humans are pathological. Our results demonstrated that VHS and CTR showed strong correlation in their measurements, suggesting that CTR, constantly used in humans, could be considered as a tool to assess the size of the heart silhouette in dogs of the poodle breed.
\end{abstract}

Keywords: CTR, VHS, heart silhouette, Poodle, echocardiography.

${ }^{1}$ Animal Science Post-Graduate Program, Federal University of Piauí (UFPI), Teresina, PI, Brazil. ${ }^{2}$ State University of Piauí, Faculty of Medical Science (UESPI), Teresina. ${ }^{3}$ Undergraduate Student of Veterinary Medicine, UFPI, Teresina. ${ }^{4}$ Department of Veterinary Morphophysiology $\&{ }^{5}$ Department of Clinical and Veterinary Surgery, UFPI, Teresina. CORRESPONDENCE: F.R. Alves [flavioribeiro@ufpi.edu.br - Tel.: +55 (86) 3215-5757]. Departamento de Morfofisiologia Veterinária, Centro de Ciências Agrárias, Universidade Federal do Piauí (UFPI), Campus da Socopo. CEP 64049-550 Teresina, PI, Brazil. 


\section{INTRODUCTION}

Veterinary cardiology has been widely divulged, especially because the search for diagnostic methods that allow early identification of heart diseases in companion animals. [16]. Several techniques are available, such as digital radiography (DR), computerized tomography (CT) and magnetic resonance (MR), that are being applied to patients with various diseases [5].

The radiographic examination of the thoracic cavity allows a fast and little invasive assessment to obtain valuable information on the lung fields, heart size and vascularization. A guideline was proposed for the normal heart size in dogs, between 2.5 and 3.5 intercostal spaces [13]. Although it is used in routine radiographic examinations these are limited mainly in the variations of the heart axis, thoracic conformation, inspiratory phase and rib overlay.

Cardiothoracic ratio (CTR) is a predictive factor for cardiac insufficiency in humans [22]. In veterinary medicine, this index is still little used [34]. Thus, there are few studies and most are directed to non-human primates [29].

The objective of the present study was to compare the vertebral heart scale (VHS) and cardiothoracic ratio (CTR) to assess changes in the size of the cardiac silhouette dogs in thoracic radiographs.

\section{MATERIALS AND METHODS}

\section{Animals}

Forty healthy male and female poodle with 2 to 15 years old and weighing between 3.1 and $11 \mathrm{~kg}$ were used. The animals were from the Veterinary Hospital of the Federal University of Piauí (UFPI).

\section{Radiographic examinations}

The animals were placed in supine and lateral decubitus, to obtain radiographic images in dorsoventral (DV) and right and left laterolateral projections of the thoracic region. A mobile x-ray equipment (INTECAL CR-7) ${ }^{1}$ was used. The images acquired on the photosensitive radiographic chassis were analyzed by digital radiographic image system (CR $30-\mathrm{X})^{1}$ installed in the Image Diagnosis Service of the University Veterinary Hospital -HVU/UFPI. They were stored on a hard disk of the computer coupled to the analysis system.

\section{VHS execution}

VHS (Vertebral Heart Scale) measurements were taken according to the protocol established by Buchanan \& Bücheler [6] that implies the sum of the heart length and heart width at its greatest diameter, comparing with the vertebral bodies from the fourth thoracic vertebra (T4). These measurements were taken and later the mean values were estimated to establish normality criteria (Figure 1a).

\section{Cardiothoracic Ratio (CTR)}

The CTR was assessed by comparing the greatest width of the heart silhouette and the distance between the thoracic walls at height $\mathrm{T} 8$, according to methodology described by Schillaci and collaborators [29] in Macaca fascicularis and by Hasan and collaborators [15] in humans (Figure 1b). The heart width was measured from the two greatest distances (ML and MR), from the vertical line that divides the limit between the right and left sides of the heart, at the point of its greatest diameter. Similarly, the thoracic width was measured at the point of greatest thoracic diameter (MTD), as follows:

$$
\mathrm{CTR}=\frac{\mathrm{MR}+\mathrm{ML}}{\mathrm{MTD}}
$$

\section{Statistical analysis}

The data were submitted to the normality of errors test (Shapiro-Wilk and Kolmogorov-Smirnov test) and then the group means were analyzed by the paired Student t-test to interpret the parameters, considering a 5\% confidence interval $(P<0.05)$.

\section{RESULTS}

The mean of the VHS and CTR for males was $9.83 \pm 0.85 \mathrm{v}$ and $0.48 \pm 0.05$, respectively. The females showed values of $9.65 \pm 0.65 \mathrm{v}$ and $0.50 \pm 0.03$, respectively (Table 1). Comparison of the means between males and females for the VHS and CTR variables did not show statistical difference $(\mathrm{P}>0.05)$. The mean of the VHS and CTR, considering males and females, was $9.72 \pm 0.73 \mathrm{v}$ and $0.48 \pm 0.04$, respectively. The VHS and weight variables showed positive and high correlation ( $\mathrm{r}=0.96)$ [Graphic 1], as CTR and weight $(\mathrm{r}$ $=0.94$ ) [Graphic 2]. The comparison between VHS and age also showed high correlation $(r=0.96)$ [Graphic 3 ], as CTR and age $(r=0.93)$ [Graphic 4]. When the VHS and CTR were compared the variables showed high correlation $(r=0.96)$ [Graphic 5]. 
G.M. Azevedo, G.T. Pessoa, L.S. Moura, et al. 2016. Comparative Study of the Vertebral Heart Scale (VHS) and the Cardiothoracic Ratio (CTR) in Healthy Poodle Breed dogs.

Acta Scientiae Veterinariae. 44: 1387.

Table 1. Values of Vertebral Heart Scale (VHS), cardiothoracic ratio (CTR), weight and age of clinically healthy poodle breed dogs, HVU/UFPI, Teresina, Piauí, Brazil.

\begin{tabular}{ccccc}
\hline & VHS & CTR & Age & Weight \\
\hline Male & $9.83 \pm 0.85(8.3-10.5)^{\mathrm{A}}$ & $0.48 \pm 0.05(0.40-0.56)^{\mathrm{A}}$ & $5.78 \pm 3.11(2-12)$ & $7.03 \pm 2.85(3.1-11)$ \\
Female & $9.65 \pm 0.65(8.6-10.5)^{\mathrm{A}}$ & $0.50 \pm 0.03(0.43-0.53)^{\mathrm{A}}$ & $8.3 \pm 4.6(2-15)$ & $6.55 \pm 1.85(3.5-9.7)$ \\
General & $9.72 \pm 0.73(8.83-10.5)$ & $0.49 \pm 0.04(0.40-0.56)$ & $7.26 \pm 4.19(2-15)$ & $6.75 \pm 2.29(3.1-11)$ \\
\hline *Means followed by different letters in the same row differ statstically & &
\end{tabular}

*Means followed by different letters in the same row differ statistically.
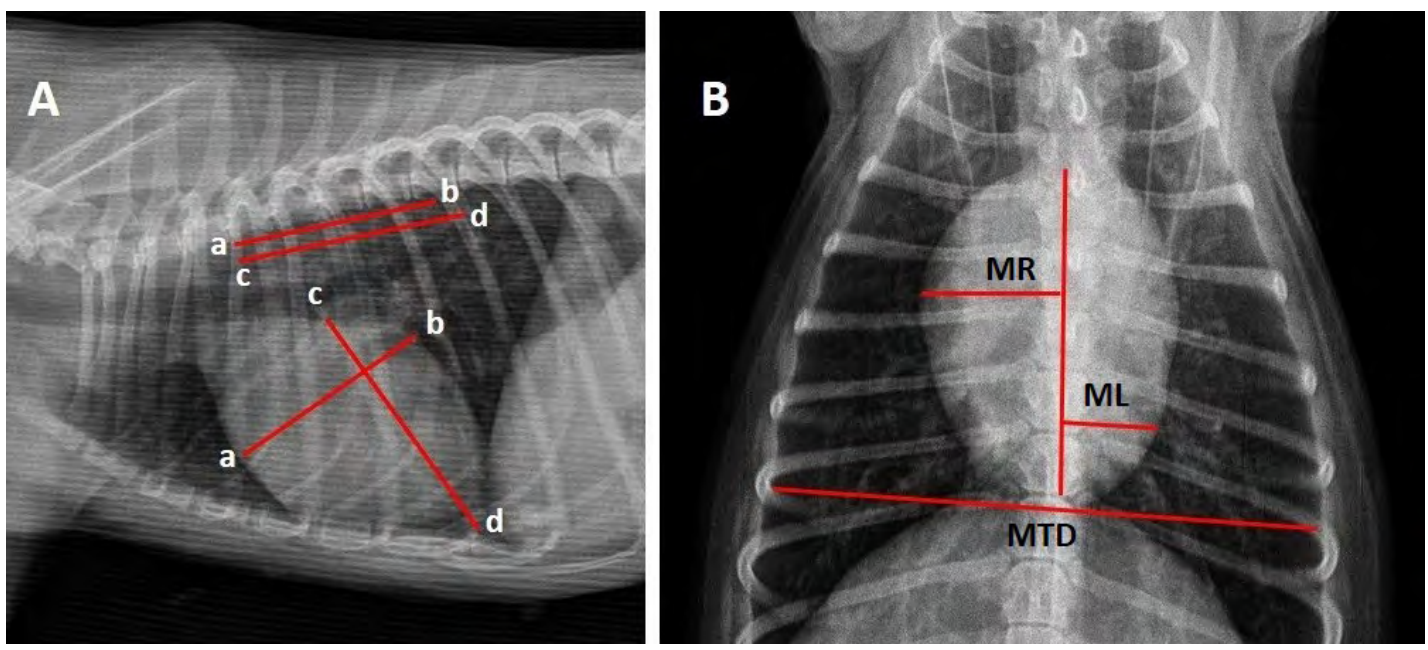

Figure 1. Digital radiographic image of the chest of a poodle breed dog. In (A) right laterolateral projection to obtain the calculation of VHS. In (B) dorsoventral projection to obtain the CTR. MTD $=$ Greatest thoracic diameter. $(M R+M L)=$ represent the two largest distances from the vertical line that divides the right and left side of the heart.

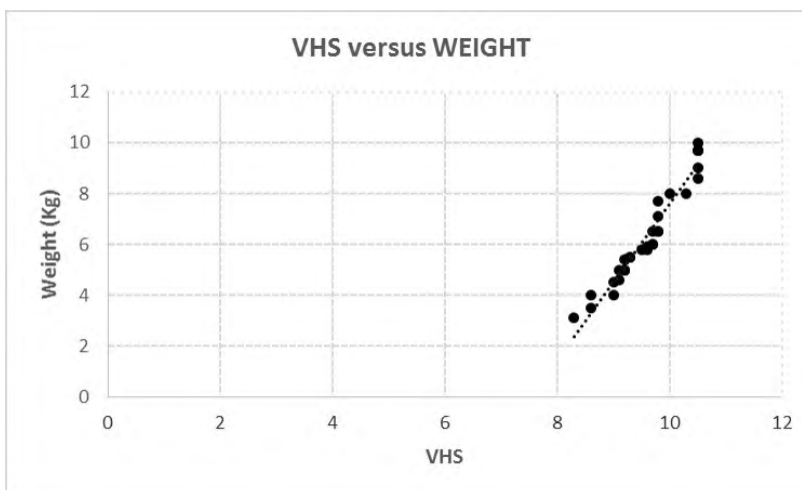

Graphic 1. Correlation between the VHS values and weight of Poodle breed dogs HVU/UFPI, Teresina, Piauí, Brazil.

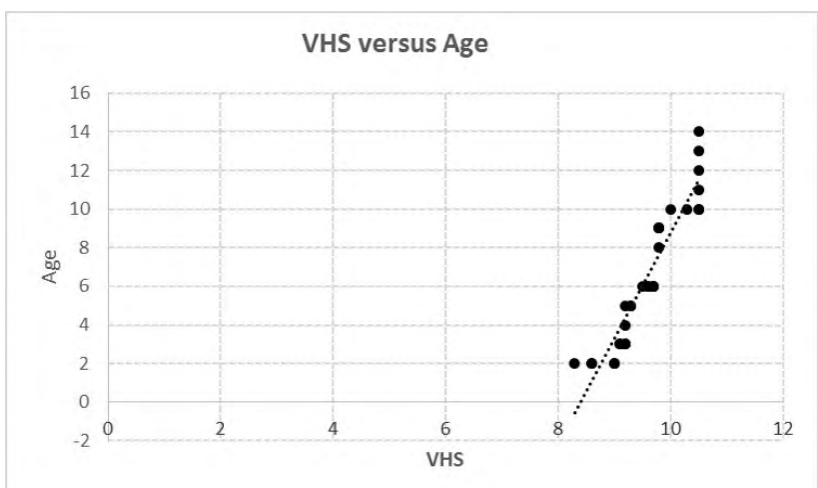

Graphic 3. Correlation between VHS values and age of Poodle breed dogs, HVU/UFPI, Teresina, Piauí, Brazil.

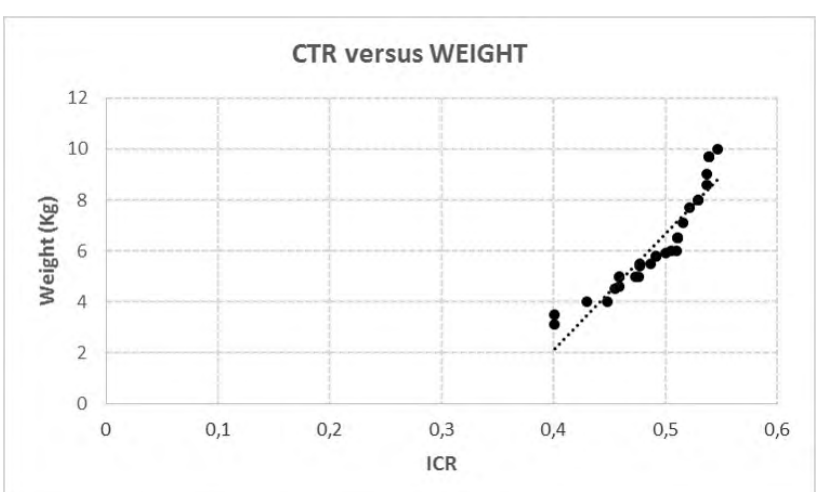

Graphic 2. Correlation between CTR values and weight of Poodle breed dogs, HVU/UFPI, Teresina, Piaú, Brazil.

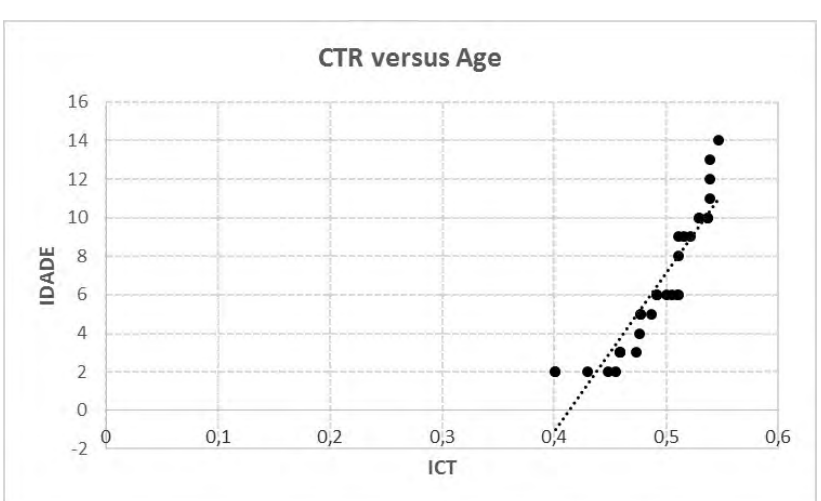

Graphic 4. Correlation between the CTR and age of Poodle breed dogs, HVU/UFPI, Teresina, Piauí, Brazil. 


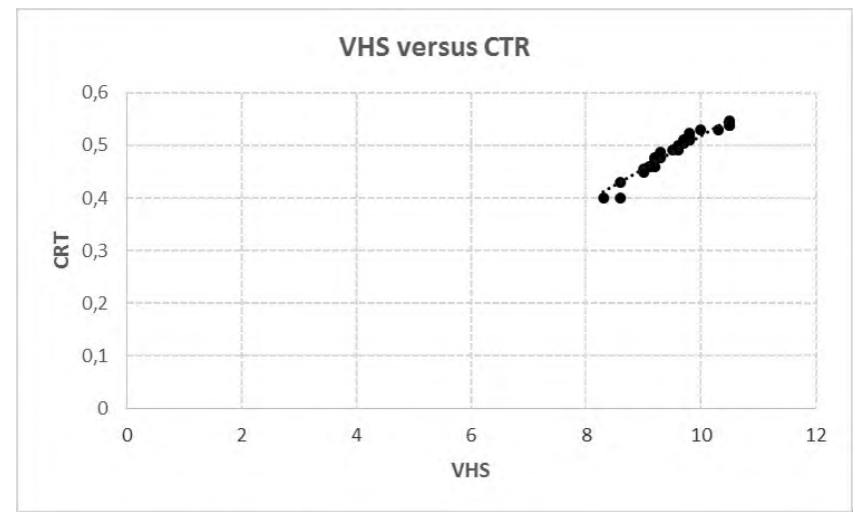

Graphic 5. Correlation between the VHS and CTR values of Poodle breed dogs, HVU/UFPI, Teresina, Piauí, Brazil.

\section{DISCUSSION}

Problems affecting the cardiovascular system in dogs are very prevalent $[11,26]$. Although congenital malformations and genetic diseases can occur, the acquired heart diseases correspond to most of the complications found [12]. In this way the congestive heart failure is a clinical syndrome frequently fatal in dogs, and can be observed in $75 \%$ of the animals that develop chronic mitral valve disease (myxomatous mitral valve degeneration) [4].

The animals studied in the present experiment were screened and considered healthy by laboratory, electrocardiographic, thoracic radiographic and echocardiographic exams. Poodle breed dogs are constantly affected by mitral valve degenerative disease with congestive heart failure (CHF). VHS increases considerably 6 to 12 months before the development of the CHF [21]. The Poodles studied, considering the universe of males and females $(P<0.05)$, presented mean VHS values of $9.72 \pm 0.73 \mathrm{v}$. Similarly, there was no significant difference between genders for VHS measured in right and left decubitus in normal dogs [10]. Similar values were found in a study of 100 clinically healthy dogs $(9.7 \pm 0.50)$, regardless of the thoracic conformation [6]. Pinto \& Iwasaki [27] established the normality standard for the breed, with mean values of 10.12 vertebras.

Thoracic radiographs of 126 dogs with known heart problems, without respiratory or cardiologic signs showed that animals with established heart problems present higher VHS values compared to healthy animals and values greater than 10.7 vertebra are a moderate sign of heart disease, with little interobservador variability [19].
In the present study, the weight variable correlated strongly with the VHS means $(r=0.96)$ and CTR $(\mathrm{r}=0.94)$ means. A similar interaction among these variables was also observed for evaluation of cardiac size in German shepherd dogs [34]. Although we used a weight variation from 3.1 to $11 \mathrm{~kg}$, the VHS values were within the reference values for adult dogs [33]. Nevertheless, there is strong influence from the thoracic confirmation on the values obtained in the VHS (Eg. Beagles: $10.3 \pm 0.40$, Whippets: $11.0 \pm 0.5$, right decubitus/11.3 \pm 0.40 left decubitus), requiring to produce reference values for several other breeds $[2,18]$, and also to research alternative measuring methods.

The cardiothoracic ratio measured for the poodles studied showed mean values of $0.48 \pm 0.05$. This method was first proposed for humans, in the clinical assessment of military personnel [8]. In humans, values below 0.5 are considered normal, while values above this may indicate the presence of cardiomegaly $[22,35]$. The CTR is intimately related to the volume of the left ventricle [31] and CTR values above 0.5 in humans are pathological $[25,28]$. Ernst and collaborators demonstrated that the CTR is an important predictor of mortality in patients with dilated cardiomyopathy, even when compared to the echocardiographic exam, considered the "gold standard in hemodynamic and myocardial function assessment" [9]. However, exams such as echocardiography still have restrictions, especially because it is operator dependent and because ultrasound equipment is needed with software to obtain the necessary measurements to estimate the evolution of the lesions [3,24]. On the other hand, the thoracic radiograph is a method commonly used to diagnose congestive heart insufficiency in dogs, and is consid- 
ered the gold standard for correlation with the visible clinical alterations $[14,30,32]$.

Although there is much research in human medicine that shows the value of the CTR as a predictor index of a bad prognostic in the evolution of heart defects [23], in veterinary medicine this index is still little used. To date there is only one report in the literature for CTR in 146 German shepherd dogs. In the German Shepherd breed, for ventrodorsal radiographs, means CTR was $30.13 \pm 1.42 \%$ at the peak of inspiration in laterolateral radiograph and $33.44 \pm 1.46 \%$ at the peak expiration [34]. However, these values are different from those observed in the poodle breed in the present experiment. This variation can be attributed to the difference between the methods used to determine the CTR, where these authors used area means, while we used linear means. In this way, the observations of the present experiment are supported most closely by that described in humans, and in veterinary medicine further studies are needed to validate the method in other dog breeds.

The animals studied in the present experiment showed high correlation between the VHS and CTR values $(r=0.96)$. Ventrodorsal radiographs promoted a greater level of distortion in the heart silhouette compared to dorsoventral radiographs, which in this context are preferred to assess heart alterations [6,7]. Degenerative mitral valve disease, among other complications, leads to heart insufficiency, progresses with various degrees of pulmonary edema and pleural effusion that often make the lateral decubitus impossible in radiographic assessment [4]. Felines affected by hypertrophic cardiomyopathy adopt sternal decubitus to find respiratory comfort [1].

To our knowledge, this is the first study that demonstrates the positive contribution correlation between VHS (index established in the veterinary clinical routine) and CTR. Thus, animals with difficulty of accepting the lateral decubitus position could be adequately assessed by the CTR, to help in the detection of heart increases.

\section{CONCLUSION}

Standardization of the CTR, compared to the VHS, is an acceptable way of obtaining an assessment of the heart size in veterinary medicine. Thus, it is suggested that both the CTR and the VHS can be used in the cardiovascular diagnosis for poodle breed dogs and for other breeds. It is also suggested that these values should be standardized for other canine breeds.

\section{MANUFACTURER \\ ${ }^{1}$ FUJIFILM $^{\circledR}$. Santa Clara, CA, USA.}

Acknowledgments. The authors thank the Diagnosis by Image Sector of the University Veterinary Hospital of the UFPI for making the animals available. They also thank the Coordenação de Aperfeiçoamento de Pessoal de Nível Superior (CAPES), for the master degree grant.

Ethical approval. This research was approved by the Committee of Ethics in Animal Experimentation -CEEA (N. 038/14) of the Federal University of Piauí (UFPI), Teresina, Piauí, Brazil.

Declaration of interest. The authors declare that they have no conflict of interest.

\section{REFERENCES}

1 Abbott J.A. 2010. Feline hypertrophic cardiomyopathy: an update. Veterinary Clinics of North America: Small Animal Practice. 40(4): 685-700.

2 Bavegems V., Van Caelenberg A., Duchateau L., Sys S.U., Van Bree H. \& De Rick A. 2005. Vertebral heart size ranges specific for whippets. Veterinary Radiology \& Ultrasound. 46(5): 400-403.

3 Bonagura J.D. \& Schober K.E. 2009. Can ventricular function be assessed by echocardiography in chronic canine mitral valve disease? Journal of Small Animal Practice. 50(1): 12-24.

4 Borgarelli M. \& Haggstrom J. 2010. Canine degenerative myxomatous mitral valve disease: natural history, clinical presentation and therapy. Veterinary Clinics of North America: Small Animal Practice. 40(4): 651-663.

5 Browne R.F., O’Reilly G. \& Mclnerney D. 2004. Extraction of the two-dimensional cardiothoracic ratio from digital PA chest radiographs: correlation with cardiac function and the tradiotional cardiothoracic ratio. Journal of Digital Imaging. 17(2): 120-123.

6 Buchanan J.W. \& Bücheler J. 1995. Vertebral scale system to measure canine heart size in radiographs. Journal of the American Veterinary Medical Association. 206(2): 194-199.

7 Buchanan J.W. 2000. Vertebral scale system to measure heart size in radiographs. Veterinary Clinics of North America: Small Animal Practice. 30(2): 379-393. 
8 Danzer C.S. 1919. The cardiothoracic ratio. American Journal of the Medical Sciences. 157(1): 513-554.

9 Ernst E.R., Shub C., Bailey K.R., Brown L.R. \& Redfild M.M. 2001. Radiographic measurements of cardiac size as predictors of outcome in patients with dilated cardiomyopathy. Journal of Cardiac Failure. 7(1): 13-20.

10 Greco A., Meomartino L., Raiano V., Fatone G. \& Brunetti A. 2008. Effect of left vs. Right recumbency on the vertebral heart score in normal dogs. Veterinary Radiology \& Ultrasound. 49(5): 454-455.

11 Haggstrom J., Hoglund K. \& Borgarelli M. 2009. Na update on treatment and prognostic indicators in canine myxomatous mitral valve disease. Journal of Small Animal Practice. 50(1): 25-33.

12 Haggstrom J., Kvart C. \& Pedersen H.D. 2005. Acquired valvular heart disease, In: Ettinger S.J. \& Feldman E.C. (Eds). Textbook of Veterinary Internal Medicine. 6th edn. St. Louis: Elsevier Saunders, pp.1022-1039.

13 Hamlin R.L., Smetzer D.L. \& Smith G.R. 1963. Radiographic anatomy of the normal cat heart. Journal of the American Veterinary Medical Association. 143(1): 957-961.

14 Hansson K., Häggström J., Kvart C. \& Lord P. 2009. Reader performance in radiographic diagnosis of signs of mitral regurgitation in cavalier King Charles Spaniels. Journal of Small Animal Practice. 50(1): 44-53.

15 Hasan M.A., Lee S.L., Kim D.H. \& Lim M.K. 2012. Automatic evaluation of cardiac hypertrophy using cardiothoracic area ratio in chest radiograph images. Computer Methods and Programs in Biomedicine. 105(2): 95-108.

16 Hemingway H., Shipley M., Christie D. \& Marmot M. 1998. Cardiothoracic ratio and relative heart volume as predictors of coronary heart disease mortality. The White hall study 25 years follow-up. European Heart Journal. 19(6): 859-869.

17 Jung G., Landwehr P., Schanzenbacher G., Faeber B. \& Lackner K. 1995. Value of thoracic radiography in the assessment of cardiac size. A comparison with left ventricular cardiography. Rofo. 162(5): 368-372.

18 Kraetschmer S., Ludwig K., Meneses F., Nolte I. \& Simon D. 2008. Vertebral heart scale in the beagle dog. Journal of Small Animal Practice. 49(5): 240-243.

19 Lamb C.R., Tyler M., Boswood A., Skelly B.J. \& Cain M. 2000. Assessment of the value of the vertebral heart scale in the radiographic diagnosis of cardiac disease in dogs. Veterinary Record. 146(24): 687-690.

20 Litster A.L. \& Buchanan J.W. 2000. Vertebral scale system to measure heart size in radiographs of cats. Journal of the American Veterinary Medical Association. 216(2): 210-214.

21 Lord P., Hansson K., Kvart C. \& Haggstrom J. 2010. Rate of change of heart size before congestive heart failure in dogs with mitral regurgitation. Journal of Small Animal Practice. 51(4): 210-218.

22 Michiue T., Ishikawa T., Sakoda S., Quan L., Li D.R., Kamikodai Y., Okazaki S., Zhu B.L. \& Maeda H. 2010. Cardiothoracic ratio in post-mortem chest radiography with regard to the cause of death. Legal Medicine. 12(2): 73-78.

23 Monfared A.B., Farajollah S.A., Sabour F., Farzanegan R. \& Taghdisi S. 2015. Comparison of radiological findings of chest X-Ray with echocardiography in determination of the heart size. Iranian Red Crescent Medical Journal. 17(1): $1-6$.

24 O’Gara P., Sugeng L., Lang R., Sarano M., Hung J., Raman S., Fischer G., Carabello B., Adams D. \& Vannan M. 2008. The role of imaging in chronic degenerative mitral regurgitation. Journal of the American College of Cardiology Cardiovascular Imaging. 1(2): 221-237.

25 Panju A., Hemmelgarn B., Nishikawa J., Cook D. \& Kitching A. 2003. A critical appraisal of the cardiovascular history and physical examination. In:Yusuf S., Cairns J.A., Camm A.J., Fallen E.L. \& Gersh B.J. (Eds). Evidence-based cardiology. 2nd edn. London: BMJ Books, pp.14-22.

26 Petrus L.C., Oliveira V.M.C., Pereira G.G. \& Larsson M.H.M.A. 2010. Avaliação dos fluxos das valvas aórtica e pulmonar com ecocardiografia Doppler pulsátil em cães clinicamente sadios. Pesquisa Veterinária Brasileira. 30(7): 586-592.

27 Pinto A.C.B.C.F. \& Iwasaki M. 2004. Radiographic evaluation of the cardiac silhouette in clinically normal Poodles through the Vertebral Heat Size (VHS) method. Brazilian Journal of Veterinary Research and Animal Science. 41(4): 261-267.

28 Rubens M. 1996. The chest x-ray in adult heart disease. In: Julian D., Camm A.J., Fox K.M., Hall R.J.C. \& PooleWilson P.A. (Eds). Diseases of the heart. 2nd edn. London: Saunders, pp.253-283.

29 Schillaci M.A., Parish S. \& Jones-Engel L. 2009. Radiographic measurement of the cardiothoracic ratio in pet macaques from Sulawesi, Indonesia. Radiography. 15(4): 29-33. 
30 Schober K.E., Hart T.M., Stern J.A., Li X., Samii V.F., Zekas L.J., Scansen B.A. \& Bonagura J.D. 2010. Detection of congestive heart failure in dogs by Doppler echocardiography. Journal of Veterinary Internal Medicine. 24(6): 1358-1368.

31 Screaton N. 2010. The cardiothoracic ratio an inaccurate and outdated measurement: new data from CT. European Radiology. 20(7): 1597-1598.

32 Shi F.Y., Qi Z., Xue K., Ito H. \& Matsuo D. 2008. Segmenting lung fields in serial chest radiographs using both population-based and patient-specificshape statistics. IEEE Transactions on Medical Imaging. 27(4): 481-494.

33 Sleeper M.M. \& Buchanan J.W. 2001. Vertebral scale system to measure heart size in growing puppies. Journal of the American Veterinary Medical Association. 219(1): 57-59.

34 Torad F.A. \& Hassan E.A. 2014. Two-dimensional cardiothoracic ratio for evaluation of cardiac size in German shepherd dogs. Journal of Veterinary Cardiology. 16(4): 237-244.

35 Weissleder R., Wittenberg J. \& Harisinghani M.G. 2011. Primer of diagnostic imaging. 5th edn. St. Louis: Elsevier/ Mosby, 156p.

36 Zhu Y., Xu H., Zhu X., Wei Y., Yang G., Xu Y. \& Tang L. 2014. Association between cardiothoracic ratio, left ventricular size and systolic function in patients undergoing computed tomography coronary angiography. Experimental and Therapeutic Medicine. 8(6): 1757-1763. 